\title{
Regional anaesthesia for cataract surgery: comparison of three techniques
}

\author{
Timo Ali-Melkkilä, Markku Virkkilä, Kari Leino, Heikki Pälve
}

\begin{abstract}
Two methods of periocular anaesthesia (PI and PII) were compared with the traditional retrobulbar block in a prospective study of $\mathbf{4 5 0}$ patients undergoing elective cataract extraction and intraocular lens implantation. A solution of local anaesthetic containing equal amounts of $2 \%$ lignocaine and $0.5 \%$ bupivacaine was used in all the groups. Hyaluronidase (75 IU/10 ml of local anaesthetic solution) was added. Three groups of patients were studied, with 150 patients in each group. The retrobulbar injection (group R).was performed with $4 \mathrm{ml}$ of the anaesthetic solution through the lower eyelid inferotemporally and a further $6 \mathrm{ml}$ was injected for seventh cranial nerve block. In the first periocular technique (group PI) the local anaesthetic was injected inferotemporally $(5 \mathrm{ml})$ through the lower lid and superonasally $(5 \mathrm{ml})$ through the upper lid. In the second periocular technique (PII) the injections were performed inferotemporally $(5 \mathrm{ml})$ and into the medial compartment $(2 \mathrm{ml})$ of the orbit at the medial canthus. Satisfactory anaesthesia could be achieved with all of these methods. Additional block because of insufficient akinesia of the muscles was required in $12 \%(18 / 150)$ in group $R$, in $19 \%(28 / 150)$ in group PI, and in $11 \%(16 / 150)$ in PII. The medial compartment technique (PII) was associated with the highest percentage of total akinesia of the muscles and lowest reblock rate. All three methods' produced sufficient analgesia during surgery and there were no differences in the requirements for additional analgesic drugs during surgery. It is concluded that the medial compartment technique represents a good alternative to retrobulbar block. (Br F Ophthalmol 1993; 77: 771-773)
\end{abstract}

The use of regional anaesthesia is increasing at the expense of general anaesthesia, and today it has become the anaesthesia of choice for the great majority of ophthalmic surgical procedures. ${ }^{1}$ Regional anaesthesia is relatively easy to perform, seems to provide excellent anaesthesia and operating conditions, and may be safer in elderly patients, who frequently exhibit several coexisting diseases. ${ }^{24}$ The regional anaesthesia techniques allow early mobilisation and discharge in patients undergoing day case surgery, ${ }^{13}$ and a recent study shows that in cataract surgery ${ }^{5}$ it is more comfortable than general anaesthesia postoperatively. Traditionally retrobulbar anaesthesia is considered to be effective but serious complications, such as retrobulbar haemorrhage, scleral perforation, optic nerve damage, and brain stem anaesthesia, have been reported. ${ }^{3}$ Periocular techniques, in which the needle lies outside the muscle cone, have been developed to lower the rate of side effects, although serious complications associated with periocular injections have been reported as well..$^{6-8}$

Several new techniques of periocular anaesthesia have been introduced recently. ${ }^{9-11}$ These techniques differ from each other in their placement of needles, but there exist only a few prospective studies evaluating their efficacy with regard to akinesia of the muscles and analgesia of the globe.$^{67}$ In the present study we have compared the features of two methods of introducing periocular anaesthesia with the standard retrobulbar technique in 450 patients undergoing elective extracapsular cataract extraction and intraocular lens implantation.

\section{Patients and methods}

A total of 450 patients having consecutive extracapsular cataract extractions with intraocular lens implants performed at the University Hospital of Turku, Finland were included in the study. Informed consent was obtained from all patients. The anaesthetic was administered in a postanaesthesia care unit separate from the operating room by two anaesthesiologists experienced in these methods. All the blocks were performed with an anaesthetic solution containing $5 \mathrm{ml}$ of $2 \%$ lignocaine with 1:100000 adrenaline and $5 \mathrm{ml}$ of $0.5 \%$ bupivacaine. Hyaluronidase, $75 \mathrm{IU}$, was added to each anaesthetic mixture.

In order to improve the reproducibility of the blocks the patients were divided into three groups in consecutive order. For the retrobulbar block (group R), $4 \mathrm{ml}$ of the anaesthetic solution was injected into the muscle cone through the inferolateral lower lid entry using a $30 \mathrm{~mm}$ sharp 23 gauge needle (Sterican $0 \cdot 60 \times 30 / 23 G$, B Braun Melsungen, Germany). In addition, the Van Lint lid block of the seventh cranial nerve was performed with $6 \mathrm{ml}$ of the solution. ${ }^{12}$

In the group having the first periocular technique (PI) a modified technique described by Fry and Henderson was used. ${ }^{10}$ After the topical anaesthesia of the conjunctiva with oxybuprocaine $0.4 \%, 5 \mathrm{ml}$ of the local anaesthetic solution was injected through the lower eyelid just above the inferior orbital rim approximately $1 \mathrm{~cm}$ medially to the lateral canthus with $25 \mathrm{~mm}$ sharp 24 gauge needle (Terumo Neolus, $0 \cdot 5 \times 25 / 25 \mathrm{G}$, Terumo Europe NV, Belgium). The needle tip was advanced in a curvilinear fashion to reach the sagittal plane of the lateral limbus at depth of $25 \mathrm{~mm}$ from the surface of the entry point. Thereafter $5 \mathrm{ml}$ of the anaesthetic solution was injected through the upper eyelid $2 \mathrm{~mm}$ medial and inferior to the supraorbital notch. Special care was taken to avoid intraconal injections. If there was any activity of the eyelids after 10 
minutes, an additional Van Lint lid block with $2 \mathrm{ml}$ of the solution was performed.

For periocular anaesthesia in group PII the first $5 \mathrm{ml}$ injection of the local anaesthetic through the lower eyelid was identical to the one in group PI. Thereafter a second injection was performed nasally at the medial canthus, medial to the caruncle with a thin 30 gauge $13 \mathrm{~mm}$ needle (Microlance 30G1/2, 0.3×13, Beckton Dickinson, Fraga, Spain). The needle was perpendicular with the sagittal plane and the tip was advanced to a depth of $13 \mathrm{~mm}$ from the surface entry point. The volume of the injectate was $2 \mathrm{ml}$.

All the blocks were performed with the eye in the primary position. Each patient was given $1 \mathrm{mg}$ lorazepam orally 1 hour before anaesthesia. A mechanical orbital compression device set at $40 \mathrm{~mm} . \mathrm{Hg}$ was applied immediately after the administration of anaesthesia for 15 minutes. An ophthalmologist, unaware of the type of anaesthesia, evaluated the blocks after 15 minutes ${ }^{3}$ according to a scoring system described by Hamilton et al. Akinesia of the orbicularis oculi muscle, inferior, superior, medial, lateral recti, as well as inferior and superior oblique muscles was assessed and assigned a score ranging from 0 to 4 . A rating of 0 was given when no movement was noticed; 1 stood for a noticeable movement (but no interference with surgery); 2 indicated slight interference; 3 marked interference; and 4 indicated inadequate akinesia and need for additional injections. If additional blocks were needed, an injection with a volume ranging from 2 to $5 \mathrm{ml}$ was given through the lower eyelid with the same needles and technique described above. The block was considered to be excellent when the score was 0 or 1 in every muscle involved, sufficient with scores 2 or 3 , and poor if additional blocks were required. During the operation the need for additional analgesic drugs was recorded and on the first postoperative visit the patients were asked whether they would have their second eye operated under regional anaesthesia.

Table 1 Demographic data of the patients (mean (SD))

\begin{tabular}{|c|c|c|c|}
\hline & $\begin{array}{l}\text { Group } R \\
(n=150)\end{array}$ & $\begin{array}{l}\text { Group PI } \\
(n=150)\end{array}$ & $\begin{array}{l}\text { Group PII } \\
(n=150)\end{array}$ \\
\hline $\begin{array}{l}\text { Age (years) } \\
\text { Weight (kg) } \\
\text { Height }(\mathbf{c m}) \\
\text { Male:female }\end{array}$ & $\begin{array}{l}76(7) \\
66(11) \\
162(8) \\
54: 96\end{array}$ & $\begin{array}{l}77(8) \\
68(13) \\
163(8) \\
49: 101\end{array}$ & $\begin{array}{l}74(9) \\
71(15) \\
165(8) \\
53: 97\end{array}$ \\
\hline $\begin{array}{l}\text { Physical status } \\
\text { ASA (I:II:III:IV) }\end{array}$ & 0:61:88:1 & $2: 52: 95: 1$ & $4: 50: 103: 3$ \\
\hline
\end{tabular}

Table 2 The total and mean scores (SD) for akinesia of the individual muscles (scale 0-4, see text for details)

\begin{tabular}{|c|c|c|c|c|}
\hline & Group $R$ & Group I & Group II & $\begin{array}{l}\text { p Value } \\
\text { (Mann- } \\
\text { Whitney) }\end{array}$ \\
\hline $\begin{array}{l}\text { Orbicularis oculi } \\
\text { Superior recti }\end{array}$ & $\begin{array}{l}0.45(0.81) \\
0.61(1.15)\end{array}$ & $\begin{array}{l}023(070) \\
0.48(1.01)\end{array}$ & $\begin{array}{l}0.28(0.83) \\
0.19(0.67)\end{array}$ & \multirow{4}{*}{$\begin{array}{l}\text { ns } \\
\text { ns } \\
R \text { vs PII } \\
p=0.008 \\
\text { PI vs PII } \\
p=0.006 \\
\text { PI vs PII } \\
p=0.0003 \\
n s \\
p=0.01\end{array}$} \\
\hline Inferior recti & $0.89(0.91)$ & $0.48(1.02)$ & $0.30(0.92)$ & \\
\hline Lateral recti & $0.38(0.88)$ & $0.61(1 \cdot 17)$ & $0.14(0.61)$ & \\
\hline $\begin{array}{l}\text { Medial recti } \\
\text { Obliques } \\
\text { Total }\end{array}$ & $\begin{array}{l}0.45(1.24) \\
0.61(0.90) \\
3.4(4 \cdot 8)\end{array}$ & $\begin{array}{l}0.83(1.45) \\
0.68(1.02) \\
3.3(5.4)\end{array}$ & $\begin{array}{l}0.15(0.7) \\
0.59(0.98) \\
1.6(3.4)\end{array}$ & \\
\hline
\end{tabular}

ns $=$ not significant .
Table 3 Quality of the blocks. Excellent block=score of each muscle 0 or 1 (scale 0-4, see text for details). Sufficient block = score of each muscle 2 or 3 . Additional block needed $=$ score 4

\begin{tabular}{lrlr}
\hline & $\begin{array}{l}\text { Group } R \\
\text { No\% }\end{array}$ & $\begin{array}{l}\text { Group PI } \\
\text { No\% }\end{array}$ & $\begin{array}{l}\text { Group PII } \\
\text { No\% }\end{array}$ \\
\hline Excellent block & $106(71)$ & $108(72)$ & $113(75)$ \\
Sufficient block & $26(17)$ & $14(9)$ & $21(14)$ \\
Additional block needed & $18(12)$ & $28(19)$ & $16(11)$ \\
\hline
\end{tabular}

The demographic data of the groups were evaluated using one way analysis of variance. For the differences between the groups with regard to block scores, frequency of additional blocks, and quality of the block, the $\chi^{2}$, Fischer's exact test, Kruskall-Wallis, and Mann-Whitney tests were used as appropriate. A p value less than 0.05 was considered significant.

\section{Results}

The groups were comparable with regard to age, weight, height, sex distribution, and ASA classification (Table 1). The mean scores and the scores for the individual muscles are shown in Table 2. There was a statistically significant difference between the mean total scores of groups R and PII, 3.4 (SD 5.0) and $1.6(3.4)$ respectively (Mann-Whitney, $\mathrm{p}=0.01$ ). In group PII the inferior, lateral, and medial muscles (IR, LR, MR) had a significantly better akinesia when compared with $R$ or PI group.

When the groups were compared with regard to the overall quality of the block (Table 3 ), the PII group had the highest percentage of excellent blocks and the lowest percentage of poor blocks, but the differences were not statistically significant. The total volumes of local anaesthetic required to achieve the akinesia in groups $\mathrm{R}, \mathrm{PI}$, and PII were $10.3 \mathrm{ml}(\mathrm{SD} 0.7), 10.8 \mathrm{ml}(1.4)$ and $8.6 \mathrm{ml}(1.5)$, respectively. The difference between group PII and the other groups was statistically significant (Mann-Whitney, $\mathrm{p}<0.001)$. In this series, no previously mentioned major complications occurred in any of the groups. Minor adverse effects (such as chemosis, lid haematomas, and conjunctival haemorrhagias) were found in all the groups. In groups R, PI, and PII conjunctival chemosis was found in $13 \%, 15 \%$, and $28 \%$ (Fisher's exact test, $\mathrm{p}=0.001$ ) and lid haematomas in $7 \%, 4 \%$, and $1 \%$ (Fischer's exact test, $\mathrm{p}=\mathbf{0 . 0 2}$ ), respectively.

During surgery fentanyl was administered intravenously to four patients in group $R$, six patients in group PI, and four patients in group PII. Only four patients preferred general anaesthesia to regional anaesthesia for the operation of their second eye. Three of them had received retrobulbar block and one periocular block (technique PII).

\section{Discussion}

In the present study we have compared the features of the two periocular techniques of regional anaesthesia with the standard retrobulbar technique in patients undergoing elective cataract surgery.

During the past few years several studies 
comparing the efficacy and side effects of retrobulbar and periocular techniques have been published. ${ }^{3679-11}$ However, there exists a great variation in the methods and local anaesthetics used which makes it rather difficult to compare the results of the separate studies. The criteria of evaluating the block quality are not always equal in these studies either. To be able to compare the motor block produced by retrobulbar and periocular anaesthesias in the present study, an effort was made to abolish the motor activity of the eyelids and extraocular muscles totally in order to achieve the ideal operating conditions. We used a scoring system, which allowed us to evaluate the motor activity of the individual muscles separately. A similar method has been used by Hamilton $e t$ al in a large retrospective study of 12000 patients comparing different techniques of regional blocks for cataract surgery. ${ }^{3}$ In their study the percentage of patients requiring block supplementation was $19.8 \%$ after the standard retrobulbar block and $24 \%$ after the peribulbar block. In our study the respective values were $12 \%$ and $19 \%$.

In a recent prospective study of Shriver et al the effectiveness of retrobulbar and peribulbar block for anterior segment surgery was evaluated. ${ }^{7}$ They found no statistically significant difference between the efficacy of the two local anaesthesia methods. The reblock rate $(6.8 \%$ after retrobulbar and $4.4 \%$ after peribulbar) was significantly lower when compared with the respective percentages in our study. However, they used larger volumes of local anaesthetics and $0.75 \%$ bupivacaine. In addition, the criteria for akinesia were not comparable. Weiss and Deichman compared the efficacy of single retrobulbar and periocular injections in 79 patients. $^{6}$ Their criteria for akinesia and supplementation of block were analogous to those of the present study. They had a reblock frequency of $21 \%$ after retrobulbar injection and $28 \%$ after periocular injection and their conclusion was that the efficacy of periocular anaesthesia was comparable with that of retrobulbar anaesthesia. The lowest reblock rate $(11 \%)$ was found in group PII, where the second periocular injection was given nasally into the medial compartment of the orbit.

As far as we know, there are no previous studies comparing this PII technique with other methods of regional anaesthesia. The satisfactory akinesia produced by combined inferotemporal and medial compartment injections can be partly explained by anatomical details. The spread of local anaesthetic after periocular injection outside the muscle cone is greatly affected by the connective tissue septa of the orbit. ${ }^{13}$ The socalled muscle cone not a well defined anatomical entity, but is instead composed of a complicated network of muscles and intermuscular connective tissue septa with communicating fat compartments. In the inferotemporal region the connective tissue septa are absent and the extracone and intracone fat compartments are in communication. In the nasal side of the medial rectus muscle the connective tissue septa and check ligament, which is located at medial canthus, form a discrete medial compartment. But above and below this ligament the connective tissue is weak forming 'hernial orifices', which lead into the upper and lower lids. ${ }^{1314}$ Thus, the efficacy of the medial compartment technique can be explained by knowing these anatomical details. The free flow of local anaesthetics from extraconal to intraconal space has been recently demonstrated with computed tomography. It appears that after periocular injection the diffusion of the anaesthetic into the muscle cone is rapid. ${ }^{15}$

In the present study none of the techniques were associated with any major complications. The most frequent side effect was conjunctival chemosis, which did not affect the surgical procedure. All the techniques were associated with acceptable patient satisfaction; additional analgesics during surgery were rarely needed and almost all the patients said they would have their second eye operated under regional anaesthesia.

It was the common experience of the authors that the medial compartment technique was the easiest to perform, especially in cases where the cooperation of the patients was impaired. In conclusion, the data of the present study suggest that the technique of periocular anaesthesia, which uses the inferolateral and medial compartment injections, is at least as effective as the traditional retrobulbar block. As this technique is easier to perform and requires lower volumes of anaesthetic solution, we feel that it is a good alternative to the retrobulbar technique.

1 Hodgkins PR, Luff AJ, Morrel AJ, Teye Botchway L, Featherston TJ, Fielder AR. Current practice of cataract extraction and anaesthesia. Brf Ophthalmol 1992; 76: 323-6.
Rubin AP. Anaesthesia for cataract surgery - time for a change? Anaesthesia 1990; 45: 717-8.

3 Hamilton RC, Gimbel HV, Strunin L. Regional anaesthesia for 12,000 cataract extractions and intraocular lens implantation procedures. Can $\mathcal{F}$ Ophthalmol 1988; 35: 615-23.

4 Steele A. Local anaesthesia for cataract surgery. Br $\mathcal{O}$ Ophthalmol 1990; 74: 195.

5 Koay P, Laing A, Adams K, Branney S, Mathison J, Freeland $\mathrm{F}$, et al. Ophthalmic pain following cataract surgery: a comparison between local and general anaesthesia. Brf Ophthalmol 1992; 76: 225-7.

6 Weiss JL, Deichmann CB. A comparison of retrobulbar and periocular anesthesia for cataract surgery. Arch Ophthalmol 1989; 107: 96-8.

7 Shriver PA, Sinha S, Galusha JH. Prospective study of the effectiveness of retrobulbar and peribulbar anesthesia for anterior segment surgery. F Cataract Refract Surg 1992; 18: $162-4$.

8 Kimble JA, Morris RE, Witherspoon CD, Feist RM. Globe perforation from peribulbar injection. Arch Ophthalmol 1987; 105: 749.

9 Davis DB, Mandel MR. Posterior peribulbar anesthesia: an alternative to retrobulbar anesthesia. Implants Ophthalmol 1986; 2: 154-6.

10 Fry RA, Henderson J. Local anaesthesia for eye surgery. The periocular technique. Anaesthesia 1989; 45: 14-7.

11 Schneider M, Faulborn J, Von Hochstetter AHC. Posterior peribulbar anaesthesia for eye surgery. Eur $\mathcal{f}$ Anaesthesia 1989; 6: 425-30.

12 Jaffe NS. Cataract surgery and its complications. 3rd ed. St Louis: Mosby, 1981: 33.

13 Koorneef $L$. Eyelid and orbital fascial attachments and their clinical significance. Eye 1988; 2: 130-4.

14 Koorneef L. Orbital connective tissue. In: Tasma W, Jeager EA, eds. Duane's foundations of clinical ophthalmology. Vol 1. Philadelphia: Lippincott, 1991

15 Ropo A, Nikki P, Ruusuvaara P, Kivisaari L. Comparison of retrobulbar and periocular injections of lignocaine by computed tomography. Br F Ophthalmol 1991; 75: 417-20. 